\title{
PNE (2001-2010), PNE (2014-2024): orientações para a Educação Profissional no Brasil
}

\author{
T. G. S. MELO'* e D. H. MOURA ${ }^{2}$ \\ ${ }^{1}$ Centro Estadual de Educação Profissional João Faustino Ferreira Neto \\ ${ }^{2}$ Instituto Federal de Educação, Ciência e Tecnologia do Rio Grande de Norte \\ tici.hp@gmail.com
}

Submetido10/03/2017 - Aceito 11/06/2017

DOI: $10.15628 /$ holos.2017.5766

\section{RESUMO}

A temática das políticas voltadas para Educação Profissional são de extrema relevância na atualidade, fundamentalmente nos marcos da expansão e privatização da mesma. Assim, este artigo tem como objetivo analisar o Plano Nacional de Educação (PNE) 2001-2010, e o Plano Nacional de Educação (PNE) 20142024, com foco na expansão e privatização da Educação Profissional. Esse artigo utilizou-se da pesquisa bibliográfica e documental. Para tanto, analisaremos dados do Instituto Nacional de Estudos e Pesquisas Educacionais Anísio Teixeira (INEP), Leis, documentos oficiais, relacionando com estudiosos como, Ciavatta (2013) Dourado (2010), Souza (2006), e Moura (2014), que nos auxiliaram na fundamentação deste trabalho, bem como nas relações estabelecidas entre o PNE 20012010, o PNE 2014-2024 e a Educação Profissional no Brasil. A partir disso, o artigo encontra-se estruturado da seguinte forma: inicialmente, será apresentada a concepção de política pública adotada; em seguida, se discutirá as relações entre o Plano Nacional de Educação 2001-2010, o Plano Nacional de Educação 2014-2024, e o processo de expansão e privatização da Educação Profissional. Finalmente, serão tecidas algumas considerações finais sobre a temática. Diante da pesquisa, observamos como resultado que, tanto o PNE 2001-2010, como o PNE 2014-2024, favoreceram, e coadunaram e/ou coadunam com o processo de expansão da Educação Profissional no Brasil.

PALAVRAS-CHAVE: Plano Nacional de Educação (2001-2010), O Plano Nacional de Educação (2014-2024), Expansão, Educação Profissional.

\section{PNE (2001-2010), PNE (2014-2024): guidelines for Professional Education in Brazil}

\section{ABSTRACT}

The themes of policies focused on Professional Education are extremely relevant at the present time, fundamentally within the framework of the expansion and privatization of it. Thus, this article aims to analyze the National Education Plan (PNE) 2001-2010, and the National Education Plan (PNE) 2014-2024, focusing on the expansion and privatization of Professional Education. This article used bibliographical and documentary research. To do so, we will analyze data from the National Institute of Educational Studies and Research Anísio Teixeira (INEP), Laws, official documents, relating to scholars such as Ciavatta (2013) Dourado (2010), Souza (2006) and Moura Helped us in the foundation of this work, as well as in the
\end{abstract}

relationships established between PNE 2001-2010, PNE 2014-2024 and Professional Education in Brazil. From this, the article is structured as follows: initially, the conception of public policy adopted will be presented; then will discuss the relationship between the National Education Plan 2001-2010, the National Education Plan 2014-2024, and the process of expansion and privatization of professional education. Finally, some final considerations on the theme will be woven. In view of the research, we observed as a result that both the PNE 2001-2010 and the PNE 2014-2024 favored, and were in line with, the process of expansion of Professional Education in Brazil.

KEYWORDS: National Education Plan (2001-2010), The National Education Plan (2014-2024), Expansion, Professional Education. 


\title{
1 INTRODUÇÃO
}

Como analisaremos políticas voltadas para a educação brasileira, trouxemos a concepção de políticas públicas, segundo Souza (2006). Para a autora, não existe uma única definição para as políticas públicas, mas é preciso compreendê-las inseridas na economia e na dinâmica social, assim como compreender suas inter-relações com o Estado (SOUZA, 2006). Nesse sentido,

\begin{abstract}
pode-se, então, resumir política pública como o campo do conhecimento que busca, ao mesmo tempo, "colocar o governo em ação" e/ou analisar essa ação (variável independente) e, quando necessário, propor mudanças no rumo ou curso dessas ações (variável dependente). A formulação de políticas públicas constitui-se no estágio em que os governos democráticos traduzem seus propósitos e plataformas eleitorais em programas e ações que produzirão resultados ou mudanças no mundo real (SOUZA, 2006 , p. 26, grifo do autor).
\end{abstract}

A autora afirma a política pública como sendo o Estado em movimento, em uma determinada direção. Portanto, entendemos que as políticas públicas, no contexto do início do século XXI, apresentam concepções características do modo de produção capitalista, com orientações também advindas de um Estado capitalista e permeada por tensões entre a classe trabalhadora e a classe detentora do capital. Segundo Souza (2006), as políticas públicas, após o âmbito da formulação desdobram-se em planos, programas, projetos. A partir do exposto, compreendemos que, quando implementadas, essas políticas públicas carregam as contradições de uma sociedade cindida em classes, ou seja, as tensões sociais.

A análise de políticas consiste em um tipo de pesquisa que, segundo Schneider (1986), busca "[...] projeção das possíveis consequências de uma ou mais políticas alternativas. [...] Essas projeções contribuem para esclarecer o impacto das políticas alternativas e reduzir a incerteza relativa aos efeitos dos diferentes cursos de ação passíveis de adoção" (SCHNEIDER, 1986, p. 354). Por conseguinte, a análise de políticas é importante para compreender seus objetivos declarados e não declarados, bem como tentar projetar consequências.

A escolha do Plano Nacional De Educação 2001-2010 (BRASIL, 2001) e do Plano Nacional De Educação 2014-2024 (BRASIL, 2014), justifica-se pela relevância desses documentos para o direcionamento da educação brasileira. Buscamos, então, analisar como estão dispostas as orientações para a educação de forma geral e, particularmente, para a expansão e a estruturação da oferta pública e privada na Educação Profissional nesses documentos. Por meio desses planos existe a possibilidade de analisarmos as Metas e Estratégias e perceber quais orientações estão expressas, ou ocultas nesses documentos. Esses planos são, sem dúvida, marcos importantes nas políticas educacionais. No entanto,

num país com um sistema capitalista marcadamente excludente, como o Brasil, com tão elevada dívida social, certamente os "planos econômicos" ou de "desenvolvimento global" e, muito menos, os Planos Nacionais de Educação não podem exercer papel determinante (mesmo quando produzam e alterem algumas evoluções), se tomados isoladamente (CALAZANS, 2011, p. 18, grifo do autor).

A ressalva apresentada, quanto à incapacidade de um plano de educação exercer papel determinante na mudança de um quadro educacional, é necessária para elucidar os limites para concretizá-los. Todavia, essa ressalva não deve desencorajar ações que sistematizem e que reflitam sobre a elevação da qualidade da educação brasileira. 
Nesse viés, no item seguinte analisaremos as vinculações entre a expansão da Educação Profissional com o Plano Nacional de Educação 2001-2010.

\title{
2 PLANO NACIONAL DE EDUCAÇÃO 2001-2010
}

De acordo com Dourado (2010, p. 682), O Plano Nacional de Educação (PNE) aprovado pela Lei no 10.172 (BRASIL, 2001) “[...] é resultado das ações da sociedade brasileira para garantir as disposições legais contidas no artigo 214 da Constituição Federal, de 1988 [...]". Por um lado, esse plano tem sua raiz histórica na concepção de direito à educação pública, gratuita e de qualidade orientada pela Constituição Federal de 1988 (BRASIL, 1988). Nesse caso, elucidamos a importância desse PNE, como um marco nas políticas públicas para a educação brasileira.

Por outro lado, o Projeto de Lei no 4.155/98 (BRASIL, 1998), foi escrito no governo de Fernando Henrique Cardoso, situado em uma década que marca o início das orientações neoliberais no Brasil. Desde sua embrionária construção, o PNE 2001-2010 apresentava concepções distintas de sociedade, trabalho, educação e formação humana, por parte dos setores envolvidos em sua formulação. Por essa razão,

\footnotetext{
o texto final aprovado traz as marcas dos embates ocorridos ao longo da tramitação da proposta, que se manifestam, especialmente, quando se trata da aplicação de recursos para garantir o alcance das metas, item que sofreu restrições mediante os nove vetos presidenciais (AGUIAR, 2010, p. 711).
}

Os embates são resultados de um contexto mais global, ou seja, uma sociedade capitalista fundamentalmente marcada pela contradição, e um contexto local, no que diz respeito as correlações de forças movidas no Brasil. Nesse viés, a Associação Nacional de Pós-Graduação e Pesquisa em Educação (Anped), envolta no processo de elaboração do PNE, fundamentou críticas à proposta, visto que não contemplava a compreensão de Sistema Nacional de Educação, e também havia um demasiado repasse de responsabilidades para as esferas municipais e estaduais, diminuindo o papel da União (AGUIAR, 2010). Historicizando ainda sobre a elaboração desse plano, é preciso compreender que,

\begin{abstract}
mesmo com a resistência de uma parcela dos segmentos progressistas e socialistas do campo educacional, nucleados em torno do Coned, o governo Fernando Henrique Cardoso, consolidando sua hegemonia política, obteve amplo consenso para implementar sua política social, aprovando um Plano Nacional de Educação - PNE que se contrapôs ao Plano Nacional elaborado pelos educadores reunidos naquele fórum e assegurou por, pelo menos, dez anos a continuidade das diretrizes e metas para a educação escolar sob a ótica do capital. Essas diretrizes e metas foram substantivamente mantidas no primeiro governo Lula da Silva, que com freqüência utiliza o novo PNE como referência. (NEVES, 2008, p. 68).
\end{abstract}

Então, o pano de fundo para a constituição dessa Lei foi a institucionalização de uma educação escolar sob a ótica do capital. Além disso, Dourado (2010) afirma que a aprovação do PNE 2001-2010 foi resultado da hegemonia das orientações governamentais em curso, em que o Governo FHC visava ao processo de reforma da educação nacional, baseada nas políticas focalizadas, com orientações eminentemente neoliberais.

Visto que buscamos compreender as políticas fundantes para a Educação Profissional, principalmente voltadas para a expansão e privatização, apontamos que esse plano coaduna para “[...] a interpenetração entre as esferas pública e privada sob a égide do mercado, o que, na 
prática, abriu espaços para a consolidação de novas formas de privatização da educação [...]" (DOURADO, 2010, p. 684). Nesse sentido, apontaremos algumas orientações mais significativas e problemáticas do PNE 2001-2010, principalmente no tocante a expansão e privatização da Educação Profissional brasileira. Observe a Figura 1.

1. Estabelecer, dentro de dois anos, um sistema integrado de informações, em parceria com agências governamentais e instituições privadas, que oriente a política educacional para satisfazer as necessidades de formação inicial e continuada da força de trabalho.

2. Estabelecer a permanente revisão e adequação às exigências de uma política de desenvolvimento nacional e regional, dos cursos básicos, técnicos e superiores da, observadas as ofertas do mercado de trabalho, em colaboração com empresários e trabalhadores nas próprias escolas e em todos os níveis de governo.

3. Mobilizar, articular e aumentar a capacidade instalada na rede de instituições de educação profissional, de modo a triplicar, a cada cinco anos, a oferta de cursos básicos destinados a atender à população que está sendo excluída do mercado de trabalho, sempre associados à educação básica, sem prejuízo de que sua oferta seja conjugada com ações para elevação da escolaridade.

4. Integrar a oferta de cursos básicos profissionais, sempre que possível, com a oferta de programas que permitam aos alunos que não concluíram o ensino fundamental obter formação equivalente.

5. Mobilizar, articular e ampliar a capacidade instalada na rede de instituições de educação profissional, de modo a triplicar, a cada cinco anos, a oferta de formação de nível técnico aos alunos nelas matriculados ou egressos do ensino médio.

6. Mobilizar, articular e ampliar a capacidade instalada na rede de instituições de educação profissional, de modo a triplicar, a cada cinco anos, a oferta de educação profissional permanente para a população em idade produtiva e que precisa se readaptar às novas exigências e perspectivas do mercado de trabalho.

7. Modificar, dentro de um ano, as normas atuais que regulamentam a formação de pessoal docente para essa modalidade de ensino, de forma a aproveitar e valorizar a experiência profissional dos formadores.

8. Estabelecer, com a colaboração entre o Ministério da Educação, o Ministério do Trabalho, as universidades, os CEFETs, as escolas técnicas de nível superior, os serviços nacionais de aprendizagem e a iniciativa privada, programas de formação de formadores para a educação tecnológica e formação profissional.

9. Transformar, gradativamente, unidades da rede de educação técnica federal em centros públicos de educação profissional e garantir, até o final da década, que pelo menos um desses centros em cada unidade federada possa servir como centro de referência para toda a rede de educação profissional, notadamente em matéria de formação de formadores e desenvolvimento metodológico.

10. Estabelecer parcerias entre os sistemas federal, estaduais e municipais e a iniciativa privada, para ampliar e incentivar a oferta de educação profissional.

11. Incentivar, por meio de recursos públicos e privados, a produção de programas de educação a distância que ampliem as possibilidades de educação profissional permanente para toda a população economicamente ativa.

12. Reorganizar a rede de escolas agrotécnicas, de forma a garantir que cumpram o papel de oferecer educação profissional específica e permanente para a população rural, levando 
em conta seu nível de escolarização e as peculiaridades e potencialidades da atividade agrícola na região.

13. Estabelecer junto às escolas agrotécnicas e em colaboração com o Ministério da Agricultura cursos básicos para agricultores, voltados para a melhoria do nível técnico das práticas agrícolas e da preservação ambiental, dentro da perspectiva do desenvolvimento autossustentável.

14. Estimular permanentemente o uso das estruturas públicas e privadas não só para os cursos regulares, mas também para o treinamento e retreinamento de trabalhadores com vistas a inseri-los no mercado de trabalho com mais condições de competitividade e produtividade, possibilitando a elevação de seu nível educacional, técnico e de renda.

Figura 1: Quadro de estratégias para a Educação Profissional no PNE 2001-2010. Fonte: BRASIL (2001).

Na primeira estratégia é evidenciada a parceria público/privada, por meio da proposição de um sistema integrado de informações, entre agências governamentais e instituições privadas. Essa parceria visa orientar as necessidades educativas, em outras palavras, significa orientar a oferta da formação inicial e continuada, a partir de uma demanda de mercado.

A expressão colaboração com empresários aparece na estratégia seguinte, corroborando a perspectiva de uma formação demandada pelo mercado. Na estratégia número 3 do PNE 20012010 (BRASIL, 2001), é colocado o intento de aumentar a capacidade instalada para o favorecimento da oferta de cursos básicos. É posto no objetivo, também, o intento de triplicar a oferta a cada cinco anos. Esse aumento, visa à população que está sendo excluída do mercado de trabalho. A estratégia está relacionada à concepção de expansão da oferta da Educação Profissional. Essa estratégia possui uma vinculação direta com os cursos ofertados pelo Programa Nacional de Acesso ao Ensino Técnico e Emprego (Pronatec) ${ }^{1}$, tendo em vista que o programa centra-se na oferta de cursos de Formação Inicial e Continuada (FIC), considerados cursos básicos, como proposto pela estratégia 3. De antemão, observamos direcionamentos que servirão de gênese do Pronatec.

$\mathrm{Na}$ estratégia número 4, é colocada a integração entre a oferta de cursos básicos profissionais e a oferta de programas que permitam a conclusão do ensino fundamental. Entretanto, essa orientação de integração não se constitui expressiva, visto que é dito na estratégia, sempre que possível. Essa estratégia 4, possui relação direta com o Proeja Fundamental, visto que tal programa abrange a Formação Inicial e Continuada de trabalhadores (FIC) ocorrendo de modo concomitante ou integrado. Nas bases de tal programa, encontra-se o compromisso com a elevação do nível de escolaridade do trabalhador. A estratégia 4 direciona-se no sentido diferente à estratégia 3 , assim como do Pronatec.

Da mesma maneira que na estratégia 3, existe na estratégia 5 o intento de expandir o número de matrículas para os cursos básicos. Há o objetivo de triplicar, a cada cinco anos, a

\footnotetext{
${ }^{1}$ Política educacional que atualmente tem centralidade na expansão da Educação Profissional. O Pronatec é formulado e implementado, em outubro de 2011, por meio do Lei n ${ }^{\circ} 12.513$. Esse programa atingiu, no ano de 2014, 8 milhões de matrículas, de acordo com o Ministério da Educação. O mesmo é responsável por ofertar cursos de Formação Inicial e Continuada (FIC) e cursos técnicos de Nível Médio. Pela conjuntura sócio-histórica no qual o programa encontra-se situado, ele apresenta diversas características que se fortalecem mutuamente e que potencializam o distanciamento da construção de uma Educação Profissional voltada para politecnia, ao tempo em que tem favorecido à reprodução do capital.
} 
oferta de formação de nível técnico aos alunos nelas matriculados ou egressos do Ensino Médio. Cabe salientar que existe um propósito de expandir paritariamente a oferta tanto para os cursos básicos, como para o nível técnico.

Na estratégia número 6 é evidenciada a necessidade "Mobilizar, articular e ampliar a capacidade instalada na rede de instituições de educação profissional, de modo a triplicar, a cada cinco anos, a oferta de educação profissional permanente para a população em idade produtiva [...]" (BRASIL, 2001, p. 38). Entretanto, reside uma dúbia interpretação, no sentindo de compreender qual a rede de instituições de Educação Profissional. Nesse aspecto, podemos pensar que está inclusa tanto a esfera pública, como a esfera privada.

Leiamos novamente a estratégia 11, "Incentivar, por meio de recursos públicos e privados, a produção de programas de educação a distância que ampliem as possibilidades de educação profissional permanente para toda a população economicamente ativa" (BRASIL, 2001, p.39). Mais uma vez, é evidenciada a parceria público/privada.

Na Estratégia 14, é proposto o estímulo ao "treinamento" e "retreinamento". A troca da palavra formação para treinamento, não é à toa. Sinaliza quais os caminhos pensados, para a formação profissional. Isso traz ranços do início do século $X X$, na tentativa de instrumentalizar a classe trabalhadora para desenvolver um ofício.

No PNE 2001-2010 não existe uma orientação à Educação Profissional para ser realizada de forma integrada, revelando opções, por exemplo, de treinamentos, de qualificação. Não é meramente uma questão semântica aleatória, é uma escolha sobre o caminho formativo pensado para a Educação Profissional.

Em meio as contradições da realidade, observamos que no decênio no qual vigorou o plano, foram realizados programas que objetivaram uma Educação Profissional Integrada, a exemplo do Brasil Profissionalizado. Isso pode ser explicado por que o PNE, mesmo sendo efetivado no governo FHC, sua práxis se deu no governo Lula (2003-2010), governo com caráter mais populista. Quanto à isso, em sua avalição do PNE 2001-2010, Dourado (2010, p. 685), elucida que a

[...] complexa relação estabelecida entre o ministério, suas secretarias e órgãos e as demais instâncias responsáveis pelas políticas educacionais nos estados e municípios (secretarias, conselhos etc.), bem como na superposição de programas e ações no campo educacional que, por vezes, estruturam programas com concepções e finalidades político-pedagógicas contraditórias, não contribuindo para o avanço das políticas e da gestão na área.

Essa observação, no âmbito das políticas educacionais, é contundente, visto que, na realidade, há uma miscelânea de concepções educacionais que, ora possibilitam movimentos na direção mais progressista, ora possibilitam movimentos de retrocessos na educação. Tudo isso, faz parte das disputas e correlações de forças.

Voltando-se para as diretrizes do PNE 2001-2010 (BRASIL, 2001), nelas estão expressas, para a Educação Profissional, uma forma de integração entre

a formal, adquirida em instituições especializadas, e a não-formal, adquirida por meios diversos, inclusive no trabalho. Estabelece para isso um sistema flexível de reconhecimento de créditos obtidos em qualquer uma das modalidades e certifica competências adquiridas por meios não-formais de educação profissional. (BRASIL, 2001, p.38). 
Nesse viés, é posto o princípio da certificação de competências. Essa integração proposta no plano, é bem distinta do princípio da formação mais geral. Ainda nas diretrizes dispostas à Educação Profissional no PNE 2001-2010, afirma-se que:

\begin{abstract}
É necessário também, e cada vez mais, contar com recursos das próprias empresas, as quais devem financiar a qualificação dos seus trabalhadores, como ocorre nos países desenvolvidos. A política de educação profissional é, portanto, tarefa que exige a colaboração de múltiplas instâncias do Poder Público e da sociedade civil (BRASIL, 2001, p. 38).
\end{abstract}

A qualificação dos trabalhadores, vista desse modo, deve ser compreendida como responsabilidade também do empresariado, ou seja, retira-se do Estado a responsabilidade perante a formação do trabalhadores.

No próximo item buscaremos maiores elos entre a expansão da Educação Profissional com o Plano Nacional de Educação 2014-2024.

\title{
3 PLANO NACIONAL DE EDUCAÇÃO 2014-2024
}

O PNE 2001-2010 deixa de vigorar em 2010, porém não se teve a aprovação sequencial de outro plano. Após longas disputas políticas, em 25 de junho de 2014, a presidente Dilma Roussef sacionou a Lei no 13.005, que aprova o Plano Nacional de Educação 2014-2024 (BRASIL, 2014). Esse, tem vigência por 10 (dez) anos, a contar da data de sua publicação. No âmbito das disputas, houve a questão da destinação dos $10 \%$ do Produto Interno Bruto (PIB) à educação, pois,

[...] durante o trâmite do PL do PNE, principalmente sobre a que público os recursos se destinariam - se à educação pública, segundo a visão da educação como direito igualitário sob a responsabilidade do Estado ou também à iniciativa privada, para os que defendem o livre mercado educacional (e que, contraditoriamente, disputam acesso a fundos públicos para garantir a lucratividade dos negócios). Nessa disputa ganhou o projeto do capital e a luta histórica pela ampliação do financiamento da educação pública foi mitigada, pois a Lei do PNE permite a utilização pela iniciativa privada dos $10 \%$ do PIB no Prouni (§ 40 do Art. 5ㅇ) e no Pronatec [...]. (MOURA, 2014, p. 361).

Sobre esse aspecto macro do PNE, os $10 \%$ do PIB destinados à educação voltaram-se a destinação tanto para o financiamento da educação pública como a educação privada. Esse constitui o pano de fundo da elaboração do PNE 2014-2024.

Em se tratando especificamente da análise da Educação Profissional, nos deteremos às Metas e Estratégias do PNE 2014-2024, que contemplem a expansão e a lógica privatizante na Educação Profissional brasileira. Observe a Figura 2.

\section{Estratégia:}

3.7) fomentar a expansão das matrículas gratuitas de ensino médio integrado à educação profissional, observando-se as peculiaridades das populações do campo, das comunidades indígenas e quilombolas e das pessoas com deficiência;

\section{Estratégia:}

8.4) expandir a oferta gratuita de educação profissional técnica por parte das entidades privadas de serviço social e de formação profissional vinculadas ao sistema sindical, de forma concomitante ao ensino ofertado na rede escolar pública, para os segmentos populacionais considerados;

Meta 10: Oferecer, no mínimo, 25\% (vinte e cinco por cento) das matrículas de educação de jovens e 
adultos, nos ensinos fundamental e médio, na forma integrada à educação profissional.

\section{Estratégias:}

10.2) expandir as matrículas na educação de jovens e adultos, de modo a articular a formação inicial e continuada de trabalhadores com a educação profissional, objetivando a elevação do nível de escolaridade do trabalhador e da trabalhadora;

10.8) fomentar a oferta pública de formação inicial e continuada para trabalhadores e trabalhadoras articulada à educação de jovens e adultos, em regime de colaboração e com apoio de entidades privadas de formação profissional vinculadas ao sistema sindical e de entidades sem fins lucrativos de atendimento à pessoa com deficiência, com atuação exclusiva na modalidade;

10.10) orientar a expansão da oferta de educação de jovens e adultos articulada à educação profissional, de modo a atender às pessoas privadas de liberdade nos estabelecimentos penais, assegurando-se formação específica dos professores e das professoras e implementação de diretrizes nacionais em regime de colaboração;

Meta 11: Triplicar as matrículas da educação profissional técnica de nível médio, assegurando a qualidade da oferta e pelo menos $50 \%$ (cinquenta por cento) da expansão no segmento público.

\section{Estratégias:}

11.1) expandir as matrículas de educação profissional técnica de nível médio na Rede Federal de Educação Profissional, Científica e Tecnológica, levando em consideração a responsabilidade dos Institutos na ordenação territorial, sua vinculação com arranjos produtivos, sociais e culturais locais e regionais, bem como a interiorização da educação profissional;

11.2) fomentar a expansão da oferta de educação profissional técnica de nível médio nas redes públicas estaduais de ensino;

11.3) fomentar a expansão da oferta de educação profissional técnica de nível médio na modalidade de educação a distância, com a finalidade de ampliar a oferta e democratizar o acesso à educação profissional pública e gratuita, assegurado padrão de qualidade;

11.5) ampliar a oferta de programas de reconhecimento de saberes para fins de certificação profissional em nível técnico;

11.6) ampliar a oferta de matrículas gratuitas de educação profissional técnica de nível médio pelas entidades privadas de formação profissional vinculadas ao sistema sindical e entidades sem fins lucrativos de atendimento à pessoa com deficiência, com atuação exclusiva na modalidade;

11.7) expandir a oferta de financiamento estudantil à educação profissional técnica de nível médio oferecida em instituições privadas de educação superior;

11.9) expandir o atendimento do ensino médio gratuito integrado à formação profissional para as populações do campo e para as comunidades indígenas e quilombolas, de acordo com os seus interesses e necessidades;

11.10) expandir a oferta de educação profissional técnica de nível médio para as pessoas com deficiência, transtornos globais do desenvolvimento e altas habilidades ou superdotação;

11.14) estruturar sistema nacional de informação profissional, articulando a oferta de formação das instituições especializadas em educação profissional aos dados do mercado de trabalho e a consultas promovidas em entidades empresariais e de trabalhadores.

Figura 2 - Quadro de metas para a Educação Profissional no PNE 2014-2024. Fonte: BRASIL, 2014.

Essas estratégias e metas nos indicam, destarte, a orientação para expandir o número de matrículas na Educação Profissional brasileira. A Estratégia 3.7, propõe o fomento da expansão das matrículas gratuitas de Ensino Médio Integrado à Educação Profissional, para as populações do campo, as comunidades indígenas e quilombolas e de pessoas com deficiência. Nessa estratégia, a referência à privatização não é explícita, mas enseja claramente essa possibilidade, pois, ao tratar de "matrículas gratuitas", pressupõe-se a existência de oferta privada, visto que a oferta pública é, obrigatoriamente, gratuita. O termo gratuito pode gerar uma relação equivocada com o termo público. Quanto a isso, Ciavatta (2013, p. 971) elucida que as instituições privadas, 
[...] mesmo as mais sérias e coerentes com a prestação de serviços para o bem comum, são constituídas de forma jurídica e social privada. Não tem os recursos nem o poder de universalizar os benefícios nos termos das políticas públicas, que implicam a lei para a universalização da medida ou serviço, orçamento do poder constituído e garantia de continuidade.

Essa ideia ajuda a distinguir o público e o gratuito. Uma oferta gratuita em uma instituição privada não sinaliza para o compromisso de ser uma oferta universalizada. Isso por que estamos em uma sociedade capitalista, que não volta-se essencialmente para as necessidades humanas.

Nesse viés, a estratégia 8.4 propõe expandir a oferta gratuita de Educação Profissional Técnica por parte das entidades privadas. A referência à privatização é explícita. Ainda, o fomento é para a forma concomitante, ou seja, privilegiando a oferta da Educação Profissional que sinaliza para um caminho formativo mais fragmentado.

Ao ler a Meta 10 do PNE, observamos um aspecto positivo quanto ao esforço de integração entre Educação de Jovens e Adultos (EJA) nos ensinos Fundamental e Médio, na forma integrada à Educação Profissional. Esse aspecto denota, ainda que de modo incipiente, um passo para a construção da formação integrada que

[...] vai além de proporcionar o acesso aos conhecimentos científicos e tecnológicos produzidos e acumulados pela humanidade. Promove o pensamento crítico sobre os códigos de cultura manifestados pelos grupos sociais ao longo da história, como forma de compreender as concepções, problemas, crises e potencialidades de uma sociedade, e para que o sujeito, a partir daí, possa contribuir para a construção de novos padrões de produção de conhecimento, de ciência e de tecnologia, voltados para os interesses sociais e coletivos (MOURA, 2010, p. 891).

Essa concepção defendida por Moura (2010) transpõe a ideia da simples orientação de instrumentalizar para o mercado de trabalho. Dessa maneira, relacionando os dados do INEP (2013) e a Meta 10 do PNE, no ano de 2013, o número de matrículas na modalidade EJA intregrada à Educação Profissional (Ensino Fundamental e Médio) era de 61.463, em um total de 1.502.514 matrículas da Educação Profissional brasileira, representando apenas 4,09\%.

Ainda segundo os dados do INEP, em 2013, comparando o total de matrículas na EJA (Ensino Fundamental e Médio) de 3.772.670, ao número de matrículas na oferta EJA integrada a Educação Profissional (Ensino Fundamental e Médio) de 54.615, temos apenas de 1,44\%. Essa percentagem é muito pequena. Desse modo, os dados atuais evidenciam que a meta 10 está distante de ser alcançada, visto que almeja $25 \%$ no total de matrículas da EJA, nos ensinos Fundamental e Médio, na forma integrada à Educação Profissional.

Sobre as estratégias da Meta 10, destacaremos alguns pontos que nos chamaram atenção. As estratégias desenvolvidas na Meta 10 evidenciam uma preocupação com a elevação das escolaridade dos jovens e adultos trabalhadores, vinculadas à Educação Profissional. Há também, de forma declarada, a necessidade de se levar em consideração as especificidades do público da EJA e de elevar a qualidade da estrutura onde se ofertam os cursos para o público da EJA. É declarado, ainda nas estratégias, o estímulo à articulação entre a formação básica e a preparação para o mundo do trabalho, buscando-se a relação dos eixos da ciência, do trabalho, da tecnologia e da cultura e cidadania.

Merece destaque, a estratégia 10.8, em que se propõe fomentar a oferta pública de Formação Inicial e Continuada para trabalhadores e trabalhadoras articulada à EJA, com a 
colaboração de instituições privadas. O embate público-privado se apresenta, evidenciando a contradição. Nesse caso, não se pode conceber que a oferta pública de educação esteja sujeita à lógica produtivista das instituições privadas. Esse talvez seja o ponto mais problemático das estratégias.

Tratando-se da Meta 11, é igualmente notória a preocupação com a expansão do número de matrículas da Educação Profissional, visto que intenta triplicar as matrículas da Educação Profissional Técnica de Nível Médio. Na Meta 11, está declarada que pelo menos $50 \%$ da expansão seja efetivada no segmento público. Isso implica em não responsabilizar o Estado pelos demais 50\%, podendo deixar a critério das necessidades do mercado educacional.

Quanto às estratégias contidas na Meta 11, analisamos que essas contemplam de forma declarada o intento de expandir as matrículas de Educação Profissional por meio das redes públicas estaduais de ensino, da Rede Federal de Educação Profissional, Científica e Tecnológica e da modalidade de educação à distância, assim como da esfera privada.

Destacamos como aspectos potencialmente positivos as estratégias que visam ao estímulo ao estágio na Educação Profissional Técnica de Nível Médio e do Ensino Médio Regular, a institucionalização de um Sistema de Avaliação da Qualidade da Educação Profissional Técnica de Nível Médio, visto que esses aspectos possibilitam uma elevação da qualidade no ensino. Lembrando que a Educação Profissional não possui um sistema de avaliação, mas há o Sistema de Seleção Unificada da Educação Profissional e Tecnológica (Sisutec), criado em 2013, originado do Sistema de Seleção Unificada (Sisu), bem como existe o Exame Nacional do Ensino Médio.

Nesse sentindo, é importante destacar o intento de expandir o atendimento do Ensino Médio Integrado gratuito para as populações do campo, de comunidades indígenas e quilombolas e para as pessoas com deficiência, grupos historicamente subalternizados. Ressaltamos, mais uma vez que a oferta gratuita não garante a priorização da oferta pública, ou seja, os cursos podem ser ofertados de modo gratuito via esfera privada. Além disso, foram também contempladas estratégias que visam ampliar investimentos em programas de assistência estudantil, gerando ações necessárias à permanência do educando. Embora os aspectos sejam potencialmente positivos, a materialização desses nessa direção depende da concepção que os orienta.

Por outro lado, algumas estratégias necessitam de maiores questionamentos. A estratégia 11.5, por exemplo, propõe aumentar o número de programas que reconheçam saberes para certificação profissional em nível técnico. $O$ ato de certificar não deve ser atividade fim. A crítica recai nesse ponto sobre o já existente reducionismo de cursos de Educação Profissional à mera certificação.

Ao dar ênfase à certificação, é negado aos sujeitos o direito a essa escolarização, à educação enquanto prática social, reduzindo-a às competências mínimas exigidas pelo mercado de trabalho. Esse aspecto vem no sentido de dissociar a Educação Básica da Educação Profissional. Desse jeito, "[...] se verifica a democratização de acesso a todos os níveis de certificação, mantendo-se a diferença qualitativa entre os percursos da classe trabalhadora e os das classes dominantes [...]" (RUMMERT; ALGEBAILE; VENTURA, 2013, p. 723). Assim, o que se tem é um abismo entre os níveis de certificação da classe trabalhadora e da classe dominante. 
A Estratégia 11.6 prevê ampliar a oferta de matrículas gratuitas de Educação Profissional Técnica de Nível Médio pelas entidades privadas de formação profissional. Esse princípio de colaboração público e privado já foi observado na Meta 10.8. Entretanto, mais preocupante ainda é a Estratégia 11.14, a qual propõe estruturar o sistema nacional de informação profissional, ligando a oferta das instituições em Educação Profissional ao mercado de trabalho. Para tanto, se institucionaliza a concepção que a Educação Profissional deve ser voltada para as demandas do Mercado de Trabalho capitalista. Propõe-se, na base da política, uma subsunção da Educação Profissional ao mercado.

Para uma melhor compreensão de onde estão distribuídas as ofertas da Educação Profissional bem como traçar um paralelo entre o público e o privado, construímos a Tabela 1, fundamentada nos dados do INEP.

Tabela 1 : Evolução do número de matrículas da Educação Profissional Técnica de Nível Médio no Brasil no âmbito Público e Privado 2007-2013²

\begin{tabular}{|c|c|c|c|c|c|c|c|c|c|c|c|}
\hline \multirow[t]{3}{*}{ Ano } & \multicolumn{9}{|c|}{ PÚBLICO } & \multirow{3}{*}{$\begin{array}{r}\text { PRIVADO } \\
\text { Total }\end{array}$} & \multirow{3}{*}{$\begin{array}{l}\text { Total } \\
\text { geral }\end{array}$} \\
\hline & \multirow[t]{2}{*}{ Concomitante } & \multirow{2}{*}{$\begin{array}{r}\text { Subse } \\
\text { quente }\end{array}$} & & \multirow{2}{*}{ Integrado } & \multirow[t]{2}{*}{ Total } & \multirow{2}{*}{$\begin{array}{r}\text { Concomi } \\
\text { tante }\end{array}$} & \multirow[t]{2}{*}{ Subsequente } & \multicolumn{2}{|c|}{ Integrado } & & \\
\hline & & & EJA & & & & & EJA & Regular & & \\
\hline 2007 & 161.230 & 160.414 & 6.132 & 71.364 & 399.140 & 155.768 & 216.198 & 3.615 & 15.188 & 390.769 & 789.909 \\
\hline 2008 & 203.667 & 160.141 & 12.000 & 115.406 & 491.214 & 175.493 & 256.158 & 2.939 & 17.113 & 451.703 & 942.917 \\
\hline 2009 & 186.694 & 196.763 & 15.276 & 154.194 & 552.927 & 119.341 & 358.316 & 4.257 & 21.637 & 503.551 & 1.056 .478 \\
\hline 2010 & 104.539 & 297.711 & 34.037 & 193.568 & 629.855 & 112.011 & 410.409 & 4.115 & 22.150 & 548.685 & 1.178 .540 \\
\hline 2011 & 94.679 & 338.953 & 37.647 & 236.129 & 707.408 & 93.893 & 465.662 & 4.324 & 21.584 & 585.463 & 1.292 .871 \\
\hline 2012 & 106.277 & 350.042 & 31.912 & 273.431 & 761.662 & 133.949 & 473.387 & 4.081 & 25.114 & 636.531 & 1.398 .193 \\
\hline 2013 & 109.392 & 328.161 & 35.404 & 312.122 & 785.079 & 200.584 & 464.524 & 5.865 & 26.268 & 697.241 & 1.482 .320 \\
\hline
\end{tabular}

Fonte: Adaptado do INEP (2013).

A partir de 2007, a esfera pública, somando as redes estadual, federal e municipal, encontra-se com o número maior de matrículas. Essa ampliação do setor público está diretamente relacionada ao Brasil Profissionalizado, Proeja e a expansão da Rede Federal de Educação Profissional, tendo em vista o lançamento desses programas no período em foco.

De acordo com a Tabela 1, entre 2007 e 2011 ocorreu um decréscimo expressivo da oferta concomitante, tanto na esfera pública como na esfera privada. Por outro lado, observamos um salto da concomitância na oferta privada entre 2011 e 2013. Buscando entender quais fatores favoreceram esse expressivo aumento, em um curto espaço de tempo, refletimos por meio de nossos estudos, que isso compreende um dos efeitos do Pronatec. O programa também tem privilegiado a oferta concomitante por meio de parcerias com os Sistemas Nacionais de Aprendizagem (SISTEMA S) e com Instituições privadas via Financiamento Estudantil. Nesse paralelo público/privado observamos, ainda, que a oferta subsequente no âmbito privado é muito expressiva. Fator esse que também atribuímos ao Pronatec.

Um importante ponto para se analisar é que, se a Meta 11 propõe triplicar as matrículas da Educação Profissional Técnica de Nível Médio, assegurando a qualidade da oferta e pelo menos $50 \%$ (cinquenta por cento) da expansão no segmento público, como explicar a Estratégia 11.7, a qual amplia a oferta do Fundo de Financiamento Estudantil à Educação Profissional

\footnotetext{
${ }^{2}$ Já inclui matrículas Pronatec Técnico de Nível Médio.
} 
Técnica de Nível Médio oferecida em instituições privadas? Não é possível fazer uma relação imediata, ou mesmo irresponsável, afirmando causa e consequência. Entretanto, o Fies tem possibilitado que investimento público fortaleça instituições privadas. A tensão entre público e privado evidencia também as contradições de uma sociedade capitalista. Assim, a Estratégia 11.7 constitui uma vinculação orgânica entre o PNE 2014-2024 e o Pronatec (MOURA, 2014).

Em um igual período, por um lado, as Metas/Estratégias sinalizam para a ampliação da oferta integrada, por outro lado, a principal política da Educação Profissional é o Pronatec, que não tem como eixo norteador a oferta integrada.

\section{CONSIDERAÇÕES FINAIS}

Corroborando ao exposto, Dourado (2010) afirma categoricamente que o PNE 2001-2010 configurou-se um plano formal, sem mecanismos de financiamento, centrado em ações e programas com uma articulação frágil com políticas mais amplas e, na realidade, não foi capaz de nortear, por exemplo, diretrizes de planejamento, gestão e efetivação, deflagrando assim, grandes desafios à educação brasileira.

Quanto ao Plano Nacional de Educação 2014-2024, o mesmo converge para o Pronatec. Portanto, expandir quantitativamente não garante a elevação do grau de escolaridade, não garante sob quais bases a articulação Educação e Trabalho ocorre. Ao frisarmos nesse trabalho, as parcerias público/privado orientadas no PNE 2014-2024, em relação à Educação Profissional, é preciso atentar para o fato de que as estratégias privatizantes estão no cerne do PNE, indo desde a Educação Infantil à Pós-graduação (MOURA, 2014).

Nesse sentido, a partir da expansão da Educação Profissional, é importante aumentar a discussão e a construção de um arcabouço teórico para esse campo, que nos possibilite refletir sobre que bases e orientações queremos esta expansão.

Convém elucidar que nos dois primeiros decênios do século XXI, temos a promulgação de dois Planos Nacionais de Educação, que evidenciam elementos significativos para a efetivação das parcerias público/privado, e que reafirmam o intento de efetivar a expansão da Educação Profissional. Segundo as metas e estratégias para a Educação Profissional, podemos perceber os direcionamentos. Os programas e ações, mais especificamente no primeiro decênio do século $\mathrm{XXI}$, ainda no governo Lula, expressaram alguns movimentos importantes para uma relativa expressividade da oferta pública e tentativas de se buscar uma formação profissional mais integrada. Movimentos esses que estão expressos principalmente nos seguintes programas: Brasil Profissionalizado, ProJovem, ProEja, e pela expansão da Rede Federal de Educação Profissional.

Finalmente o Plano Nacional de Educação 2014-2024 está em vigor, merecendo um envolvimento da sociedade civil, assim como a presença do Estado no monitoramento, e na avaliação dessa política.

\section{REFERÊNCIAS}

AGUIAR, Márcia Angela da S. (2010). Avaliação do plano nacional de educação 2001-2009: questões para reflexão. Revista Educação e Sociedade, Campinas, 31 (112), 707-727. 
BRASIL. (1988) Constituição (1988). Constituição da República Federativa do Brasil. Brasília, DF: Senado Federal: Centro Gráfico.

BRASIL. (2016). Lei n. 10.172, de 9 janeiro de 2001. Institui o Plano Nacional de Educação e dá outras providências. Diário Oficial da União, Brasília, 2001. Recuperado em 29 março 2016 de http://www.planalto.gov.br/ccivil_03/leis/leis_2001/l10172.htm

BRASIL. (2014). Lei no 13.005, de 25 de junho de 2014. Aprova o Plano Nacional de Educação PNE e dá outras providências. Brasília. Recuperado em 20 março 2016, de www.planalto.gov.br

CALAZANS, M. J. (2011). Planejamento da Educação no Brasil - novas estratégias em busca de novas concepções. In. KUENZER, Acácia Z. \& GARCIA, Walter Planejamento e educação no Brasil. (8a ed). São Paulo: Cortez.

CIAVATTA, M. (2013). O regime de colaboração e o ensino médio: uma análise de contexto. Revista Educação \& Sociedade, 34 (124), 961-978.

DOURADO, L. F. (2001). A Reforma do estado e as Políticas de Formação de Professores nos anos 90. In. DOURADO, L. F. \& PARO, V. H. (org). Políticas Públicas \& Educação Básica. São Paulo: Xamã, 23 (80), 234-252.

DOURADO, L. F. (2010). Avaliação do plano nacional de educação 2001-2009: questões estruturais e conjunturais de uma política. Revista Educação e Sociedade, Campinas. 31 (112), 677-705.

INSTITUTO NACIONAL DE ESTUDOS E PESQUISAS EDUCACIONAIS ANÍSIO TEIXEIRA. (2013). Censo da educação básica: 2012. Resumo técnico. Brasília :INEP.

KUENZER, A. Z. (2005). Exclusão includente e inclusão excludente: a nova forma de dualidade estrutural que objetiva as novas relações de educação e trabalho. In. SAVIANI, D.; SANFELICE, J.L. \&LOMBARDI, J. C. (org.). Capitalismo, trabalho e educação. (3a ed). Campinas: autores Associados.

MOURA, D. H. (2014) Educação Básica e Profissional no PNE (2014-2024) Avanços e contradições. Revista Retratos da Escola, Brasília, 8 (15), 353-368.

NEVES, L. M. W. (2008). O Mercado do Conhecimento e o Conhecimento Para o Mercado. Rio de Janeiro: Fiocruz.

RUMMERT, S. M., ALGEBAILE, E. \& VENTURA, J. (2013). Educação da classe trabalhadora brasileira: expressão do desenvolvimento desigual e combinado. Revista Brasileira de Educação. Rio de Janeiro. 18 (54), 717-799.

SCHNEIDER, A. L. (1986). The evolution of a policy orientation for evaluation research: a guide to practice. Public Administration Review, 46 (4), 353- 363.

SOUZA, C. (2006). Políticas Públicas: uma revisão da literatura. Revista Sociologias, Porto Alegre, $16(1)$. 